\title{
Low Dose Irbesartan Has a Renoprotective Effect as High Dose Ramipril in Diabetic Rats Treated with Insulin
}

\author{
Abdulmonim A. Alqasim1, Sami H. Hammadi2, Ghazi A. Bamagous ${ }^{3}$, \\ Essam Eldin M. Noureldin', Hussam H. Madi ${ }^{5}$ \\ ${ }^{1}$ Department of Physiology, Faculty of Medicine, Umm-Alqura University, Makkah, Saudi Arabia \\ ${ }^{2}$ Department of Internal Medicine, Faculty of Medicine, Umm-Alqura University, Makkah, Saudi Arabia \\ ${ }^{3}$ Department of Pharmacology \& Toxicology, Faculty of Medicine, Umm-Alqura University, Makkah, \\ Saudi Arabia \\ ${ }^{4}$ Department of Biochemistry, Faculty of Medicine, Umm-Alqura University, Makkah, Saudi Arabia \\ ${ }^{5}$ Department of Pathology, Faculty of Medicine, Umm-Alqura University, Makkah, Saudi Arabia \\ Email: aaqasim@uqu.edu.sa,Hammady.samy@gmail.com
}

Received 11 September 2015; accepted 10 November 2015; published 13 November 2015

Copyright (C) 2015 by authors and Scientific Research Publishing Inc.

This work is licensed under the Creative Commons Attribution International License (CC BY).

http://creativecommons.org/licenses/by/4.0/

c) (i) Open Access

\begin{abstract}
Objectives: The aim of this study is to compare the efficacy of the anti-angiotensinic drug, ramipril and irbesartan on the vascular protection of kidneys of streptozotocin (STZ)-induced diabetic rats (DR). Methods: 110 male albino rats were divided into 7 main groups. Group-1 (10 normal control rats; NC). Group-2 (10 rats) was injected intra-peritoneally with STZ (Diabetic Rats; DR). Group-3 (10 DR) is controlled by insulin. Groups 4 to 7 (20 DR), each is subdivided into two subgroups that received either low or high dose of ramipril or irbesartan with or without insulin. Two months post treatment, rat-tail blood was collected to measure: Fasting blood sugar, HbA1c, total serum proteins, albumin and lipid profiles. Urine was collected to measure albuminuria. Kidneys were isolated for histopathological study. Results: Biochemically, both ramipril and irbesartan (without insulin) lowered albumin concentration in urine samples especially at high doses. Histopathologically, there is no beneficial response of both drugs without insulin. Combination of insulin together with either drug has beneficial effects biochemically and histopathologically at high doses. Low dose irbesartan only has renoprotective effect in DR treated with insulin. The other biochemical parameters showed negligible response to both drugs. Conclusion: Low dose irbesartan and high doses of both drugs have renoprotective effect in DR treated with insulin.
\end{abstract}

\section{Keywords}

Diabetic Nephropathy, Albuminurea, Ramipril, Irbesartan 


\section{Introduction}

Diabetic nephropathy occurs in $20 \%-40 \%$ of patients with diabetes and is the single leading cause of end stage renal disease (ESRD). Persistent albuminuria in the range of $30-299 \mathrm{mg} / 24 \mathrm{~h}$ has been shown to be an early stage of diabetic nephropathy in type 1diabetes (T1D) and a marker for development of nephropathy in type 2 diabetes (T2D). It is a well-established marker of increased cardiovascular disease (CVD) risk [1]. Patients with persistent albuminuria (30 - $299 \mathrm{mg} / 24 \mathrm{hrs}$.) who progress to more significant levels (300 mg/24hrs.) are likely to progress to ESRD [2]. A numbers of interventions have been demonstrated to reduce the risk and slow the progression of renal disease. Intensive diabetes management with the aim of achieving near-normoglycemic level has been shown to delay the onsetand progression of albuminuria in patients with T1D [3] and T2D [4] [5]. The UKPDS provided strong evidence that control of high blood pressure can reduce the development of nephropathy [6].

In addition, large prospective randomized studies in patients with T1D have demonstrated that achievement of lower levels of systolic blood pressure $(<140 \mathrm{mmHg}$ ) resulting from treatment using angiotensin converting enzyme (ACE) inhibitors provides a selective benefit over other classes of antihypertensive drugs in delaying the progression of albuminuria and can slow the decline in glomerular filtration rate (GFR) in patients with higher levels of albuminuria [7] [8]. In T2D with hypertension and normal urinary albumin, renin angiotensin aldosterone system (RAAS) inhibition has been shown to delay the onset of elevated albuminuri [9] [10]. In the latter study, there was an unexpected higher rate of fatal cardiovascular events with olmesartan among patients with preexisting chronic heart disease. ACE inhibitors have been shown to reduce major CVD outcomes such as myocardial infarction (MI), stroke and death, in patients with diabetes [11], thus further supporting the use of ACE inhibitors in patients with elevated albuminuria. Angiotensin receptor blockers (ARBs) have conflicting evidences in preventing onset of elevated albuminuria in normotensive patients with T1D and T2D [12] [13]; however, ARBs have been shown to reduce the progression rate of albumin levels excretion as well as ESRD in patients with T2D [14]. In patient with nephropathy, ARBs have a smaller magnitude of rise in potassium compared with ACE inhibitors [15].

In the absence of side effects or adverse events (e.g., hyperkalemia or acute kidney injury), it is suggested to titrate up to the maximum approved dose for the treatment of hypertension. Combinations of drugs that block the RAAS (e.g., an ACE inhibitor plus an ARB, a mineralocorticoid antagonist, or a direct renin inhibitor) provide additional lowering of albuminuria [16]. However, such combinations have been found to provide no additional cardiovascular benefit and have higher adverse event rates [17].

The aim of this work is to compares the vascular protective effects of the ACE-inhibitor, Ramipril, versus the ARB, Irbesartan, in low and high doses on kidneys of diabetic rat modelstreated or non-treated with insulin.

\section{Methods}

\subsection{Induction of DM}

DM in rats was induced by intra-peritoneal (i.p.) administration of nicotinamide (NAD) (230 mg/kg), 15 min prior to the single dose of streptozotocin (STZ) $(65 \mathrm{mg} / \mathrm{kg}$, i.p.) [18]. Control animals were received an equal volume of saline. The STZ solution contained STZ dissolved in saline with a sodium citrate buffer, $\mathrm{pH}$ 4.0. The blood glucose levels (by using standard diagnostic kits) were recorded to monitor thedegree of diabetes.

\subsection{Groups and Treatments}

One hundred and ten male albino rats were used in this study. They were divided into 7 main groups. Group (1) was served as control, which received no medications. Group (2) was diabetic induced rats as mentioned above. Group (3) was controlled by insulin after induction of DM. The first three groups consisted of 10 rats each.

Groups from the fourth to the seventh consisted of 20 diabetic induced rats, and further subdivided as follows: group (4a) consisted of 10 rats and treated orally with low dose of ramipril $(0.3 \mathrm{mg} / \mathrm{Kg})$ for 60 days. Group (4b) consisted of 10 rats and treated orally with low dose of ramipril $(0.3 \mathrm{mg} / \mathrm{Kg})$ and insulin for 60 days. Group (5a) consisted of 10 rats and treated orally with low dose of irbesartan $(15 \mathrm{mg} / \mathrm{Kg})$ for 60 days. Group (5b) consisted of 10 rats and treated orally with low dose of irbesartan $(15 \mathrm{mg} / \mathrm{Kg})$ and insulin for 60 days. Group (6a) consisted of 10 rats and treated orally with high dose of ramipril $(1.0 \mathrm{mg} / \mathrm{Kg})$ for 60 days. Group (6b) consisted of 10 rats and treated orally with high dose of ramipril $(1.0 \mathrm{mg} / \mathrm{Kg})$ and insulin for 60 days. Group (7a) consisted 
of 10 rats and treated orally with high dose of irbesartan (30 mg/Kg) for 60 days. Group (7b) consisted of 10 rats and treated orally with high dose of irbesartan $(30 \mathrm{mg} / \mathrm{Kg})$ and insulin for 60 days. The dose of insulin was calculated according to the weight of each rat and the blood glucose level.

\subsection{Biochemical Measurements}

Two months post treatment, rat-tail blood was collected to measure: fasting blood sugar level (FBS), glycosylated hemoglobin (HbA1c), total and free serum proteins (Albumin \& Globulin) and lipid profile. Twenty four hours urine samples were collected for complete urine analysis and albuminurea.Measurements of glucose, HbA1c, serum total protein and albumin, total cholesterol (TC), triglycerides (TG), high density lipoprotein cholesterol (HDL-C) and low density lipoprotein cholesterol (LDL-C) were done using the standard procedures and available commercial kits in a fully automated system (COBAS integra 400 plus).Cholesterol CHOD-PAP, triglycerides GPO-PAP, LDL-C plus second generation, HDL-C plus third generation and reagents (Roche Diagnostics, Indianapolis, IN) were used on the Chemistry Analyzer to determine levels of TC, TG, LDL-C and HDL-C, respectively. All assays were done following the recommended procedures for instrument operation, calibration, quality control, and assay guidelines. The instrument was calibrated using calibrator for automated systems (Roche Diagnostics) for glucose, TC and TG, and calibrator for automated systems lipids (Roche Diagnostics) for LDL-C and HDL-C. Results were expressed for all parameters in mg/dl. Except for HbA1c, where it was expressed as percentage of glycosylated hemoglobin [19].

Estimation of microalbuminuria (MA) levels by immunoassay classic quantitative assay for detection of antigen antibody reaction using a labeled substance to measure the binding of the unlabeled substance to a specific antibody or other receptor. The auto analyzer measures the change in absorbency at $380 \mathrm{~nm}$ spectral wavelength,and the value obtained is proportional to the urine albumin sample.

\subsection{Histopathological Examination}

All specimens were fixed in 10\% formalin, embedded in paraffin and stained with heamatoxylin and eosin (H\&E) stain and periodic acid Schiff (PAS) staining. Representative sections from each case was examined by light microscope for glomerular basement membrane (GBM) thickening throughout the entire length \& mesangial matrix along mesangial cell proliferation and presence or absence of nodular glomerulosclerosis.

\subsection{Statistical Analysis}

All statistical analyses were performed using the SPSS program (version 16). All quantitative data are described as the mean + SD. Comparisons between the control group and all other groups were performed using the Student's $t$ test or the Mann-Whitney $\mathrm{U}$ test, depending on the distribution of the data. The Kruskal-Wallis $\mathrm{H}$ test was used when comparing all groups, as some of the data were not normally distributed. Statistical significance was defined as $P<0.05$.

\section{Results}

\subsection{Fasting Blood Sugar}

Table 1 and Figure 1 show that FBS in diabetic rats or that received low or high dose ramipril or irbesartan have significant rise in FBS as compared to normal rats $(P<0.05)$. Diabetic rats that received both drugs in low or high doses and treated with insulin did not show any significant difference from control group. Treated diabetic rats with insulin significantly lowered blood glucose levels as compared to diabetic rats $(P<0.05)$ and administration of either drug (alone without insulin) have insignificant effect on blood glucose levels.

\subsection{Glycosylated Hemoglobin}

Table 1 and Figure 2 Show that HBA1c\% in diabetic rats; taking low or high doses of ramipril or irbesartanwithout insulin have significantly higher levels of HBA1cas compared to normal non-diabetic rats. Treated diabetic rats with insulin and on low dose ramipril had little significant elevation of HBA1c as compared to normal non-diabetic rats. However treatment of diabetic rats with insulin whether taking low or high dose of either drug significantly lowered the \% of HBA1c as compared to control diabetic rats. It appears that administration of 


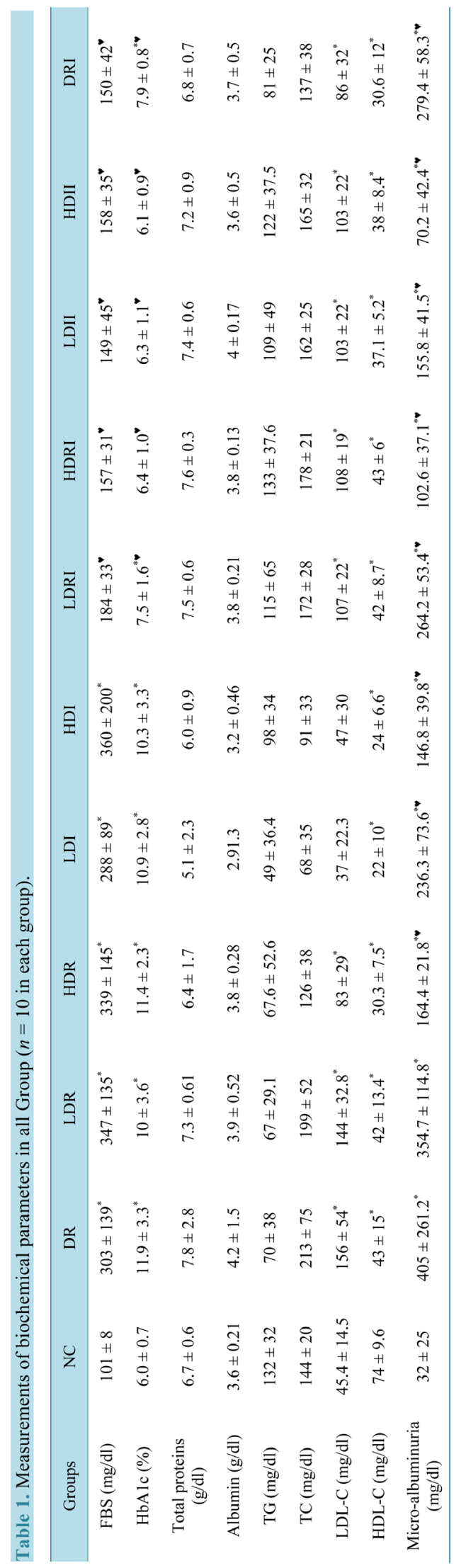




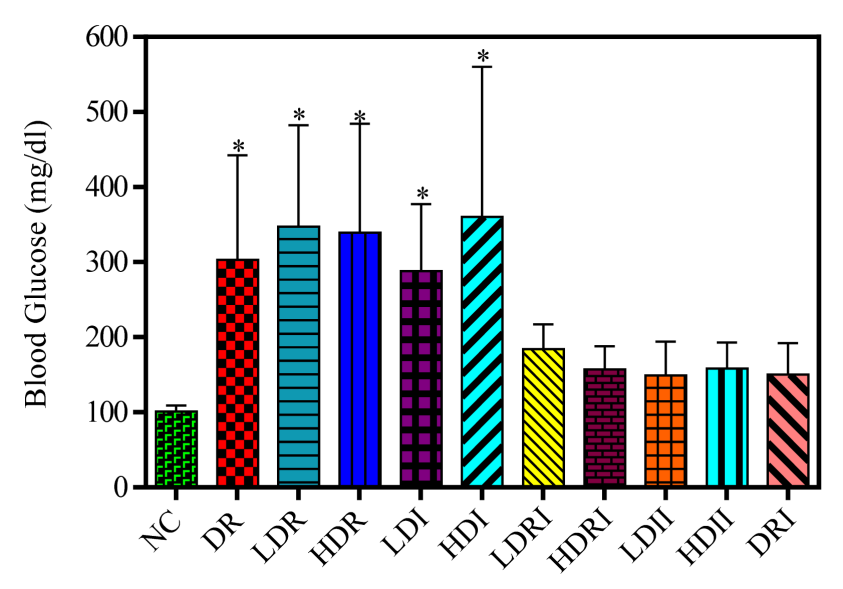

Figure 1. Measurement of FBS in diabetic rats receiving low or high dose of ramipril, or low or high dose of irbesartan in the presence or absence of insulin and compared with control groups $(n=10)$.

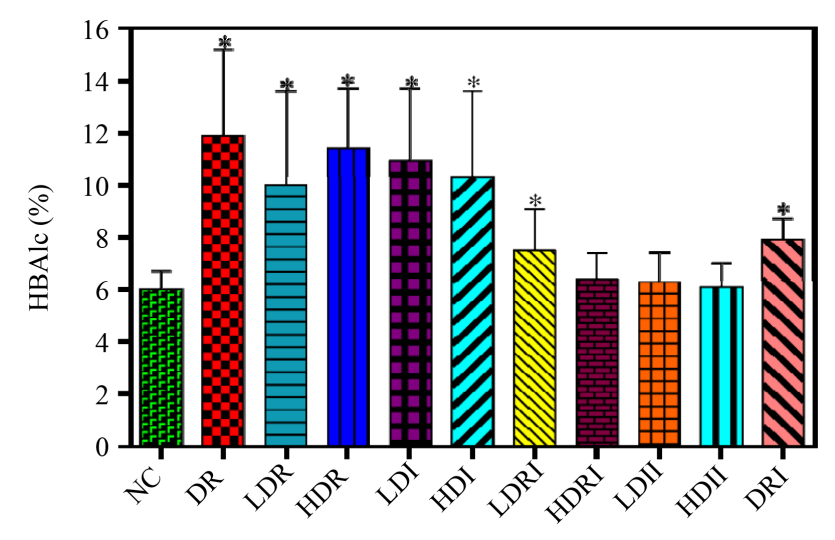

Figure 2. Percentage of HbA1c in diabetic rats receiving low or high dose of ramipril, or low or high dose of irbesartan in the presence or absence of insulin and compared with control groups $(n=10)$.

either drug alone without insulin has no loweringeffect on HbA1c in diabetic rats.

\subsection{Albuminuria}

Table 1 and Figure 3 showed that biochemically, both ramipril and irbesartan (without insulin) lowered albumin concentration in urine samples especially at high doses. Histopathologically, showed no beneficial response of both drugs without insulin. Combination of insulin together with either drug has beneficial effects biochemically and histopathologically at high doses. Low dose irbesartan only has renoprotective effect in DR treated with insulinas compared to normal non-diabetic rats $(P<0.05)$. Non-insulin treated diabetic rats treated with low or high dose of ramipril or irbesartan have significantly lower urine albuminuria as compared to diabetic rats $(P<0.05)$. Similarly, diabetic rats treated with insulin and low or high dose of ramipril or irbesartan have significantly lower urine albuminuria as compared to diabetic rats $(P<0.05)$. It appears that low dose irbesartan in non-insulin treated diabetic rats and low and high doses of either drug in insulin treated diabetic rats have more significant lowering effects on urine MA as compared to diabetic rats taking low dose ramipril without insulin. Figure 4 shows that FBS and urine albuminuria are apparently matching each other (i.e. the higher the level of FBS, the higher the level of albuminuria and vice versa). Low or high dose irbesartan has more significant lowering effect on urine albuminuria especially in insulin treated groups. Low dose ramipril in non-insulin treated rat appears to have less lowering effect on albuminuria as compared to all other insulin treated and 


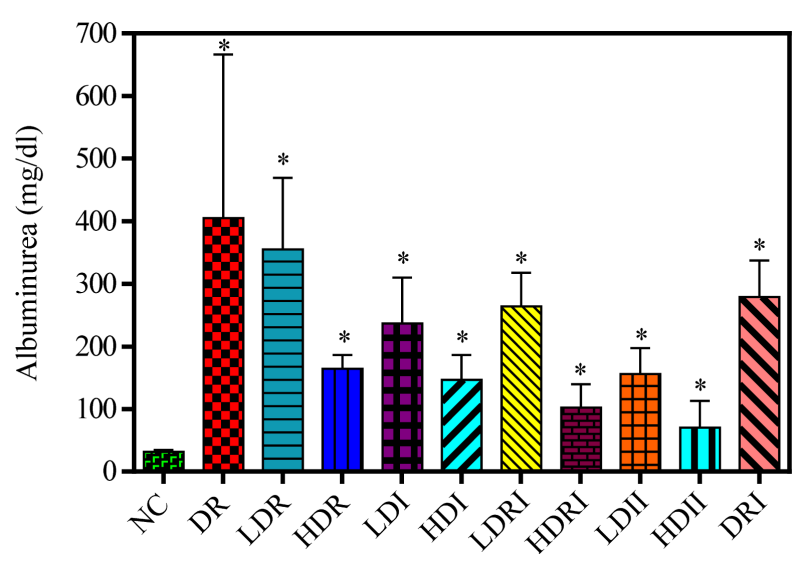

Figure 3. Measurement of albuminuria in diabetic rats receiving low or high dose of ramipril, or low or high dose of irbesar$\tan$ in the presence or absence of insulin and compared with control groups $(n=10)$.

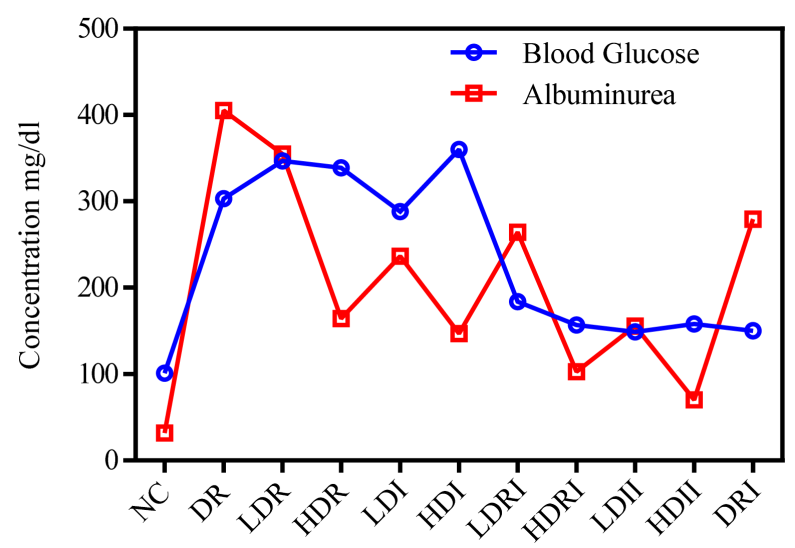

Figure 4. Correlation between the FBS and albuminuria in control groups and in diabetic rats receiving low or high dose of ramipril, or low or high dose of irbesartan in the presence or absence of insulin $(n=10)$.

non-insulin treated rats.

\subsection{Lipid Profile}

Only LDL-C and HDL-C showed significant changes in lipid profile pattern of the rats studied. LDL-C sig. increased in diabetic rats treated with insulin or not and either taking ramipril or irbesartan or not except rats treated with low and high doses of irbesartan without insulin, as compared to normal control rats. HDL-C sig. decreased in diabetic rats treated with insulin or not, taking either drug in low or high dose or not as compared to normal control rats in most of the groups studied (Table 1, Figure 5).

\subsection{Total Serum Proteins and Albumin}

Table 1 and Figure 6 show that neither induction of diabetes in rats nor their treatment with insulin or the addition of either drug, affect serum protein or albumin levels in all groups studied as compared to normal non-diabetic rats.

\subsection{Histopathology}

Histopathological study of all groups shows that light microscopic examination of LDR group demonstrated 


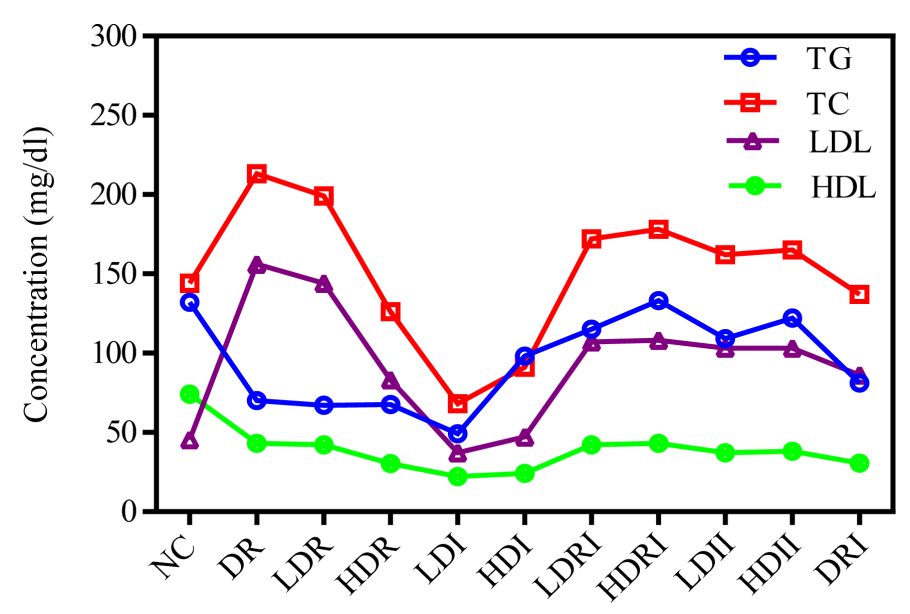

Figure 5. Level of TG, TC, LDL-C and HDL-C in control groups and in diabetic rats receiving low or high dose of ramipril, or low or high dose of irbesartan in the presence or absence of insulin $(n=10)$.

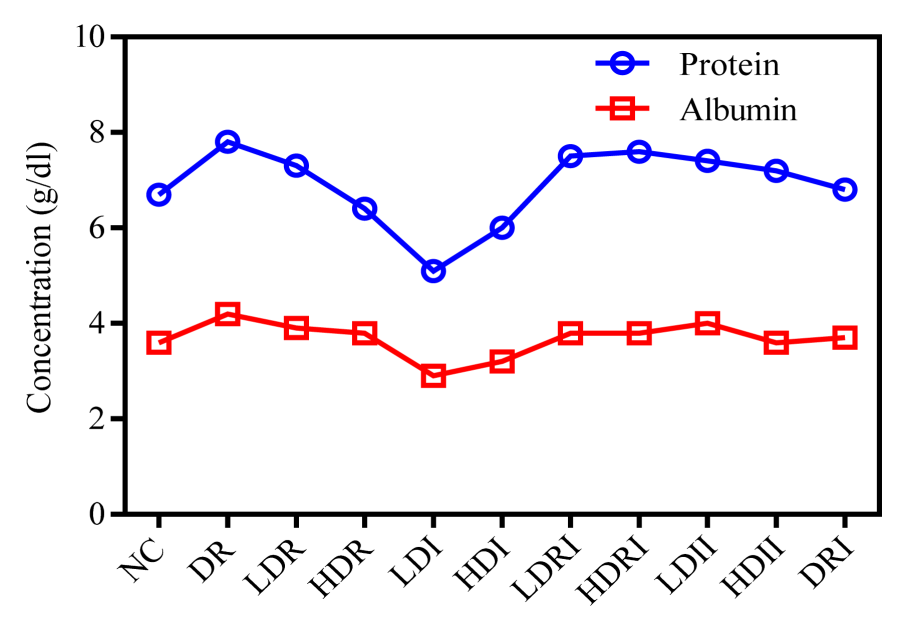

Figure 6. Level of serum proteins and albumin in control groups and in diabetic rats receiving low or high dose of ramipril, or low or high dose of irbesartan in the presence or absence of insulin $(n=10)$.

glomerular basement membrane (GBM) thickening throughout the entire length of diffuse increase in mesangial matrix along mesangial cell proliferation with no improvement in diabetic changes (Figure 7(a)). Similarly, HDR group shows GBM thickening throughout the entire length of diffuse increase in mesangial matrix along mesangial cell proliferation with no marked improvement in diabetic changes (Figure 7(b)). LDRI group shows slight GBM thickening throughout the entire length and some increases in mesangial matrix along mesangial cell proliferation with little improvement in diabetic changes (Figure 7(c)). HDRI group shows slight GBM thickening throughout the entire length and slight increases in mesangial matrix along mesangial cell proliferation with an improvement in diabetic changes (Figure 7(d)).

Histopathological examination of LDI and HDI groups shows GBM thickening throughout the entire length and diffuse increase in mesangial matrix along mesangial cell proliferation with no marked improvement in diabetic changes (Figure 7(e)_and Figure 7(f)). Interestingly, LDII and HDII groupsshow absence of GBM thickening throughout the entire length and there is no increase in mesangial matrix along mesangial cell proliferation with marked improvement in diabetic changes (Figure 7(g) and Figure 7(h)).

\section{Discussion}

Despite being increasingly recognized as a CV risk factor, the definition of MA was based on its ability to predict 


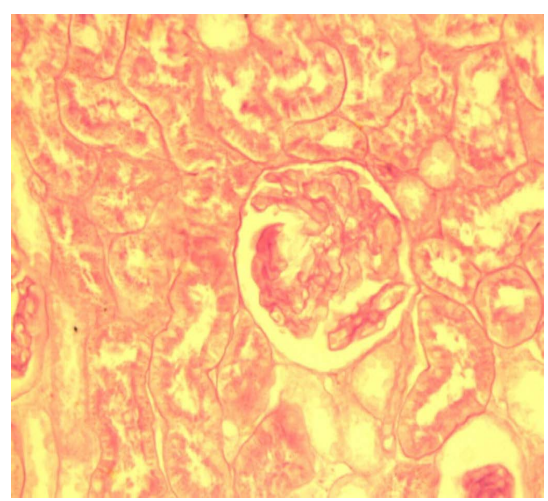

(a)

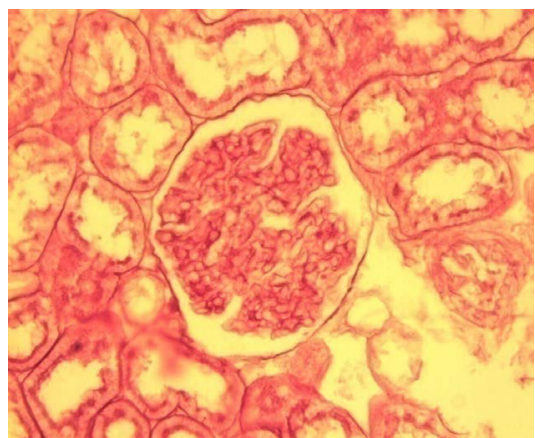

(c)

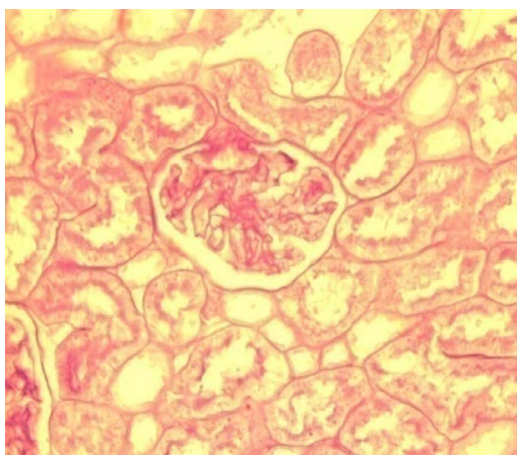

(e)

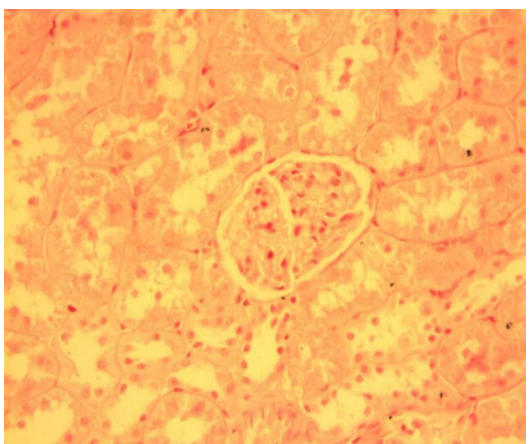

(g)

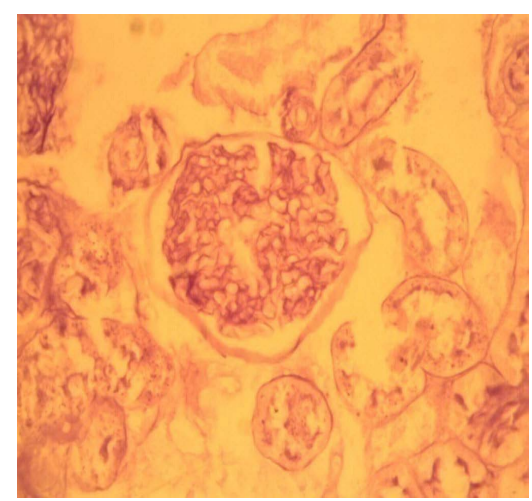

(b)

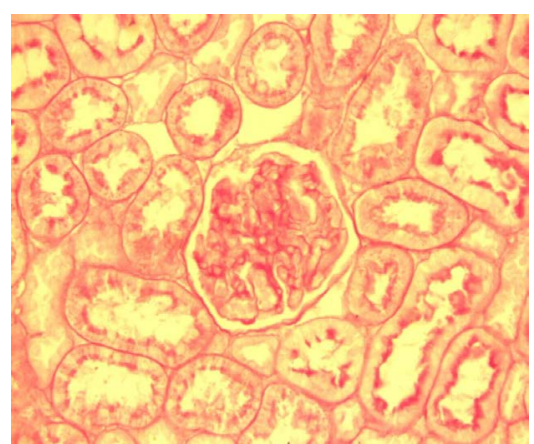

(d)

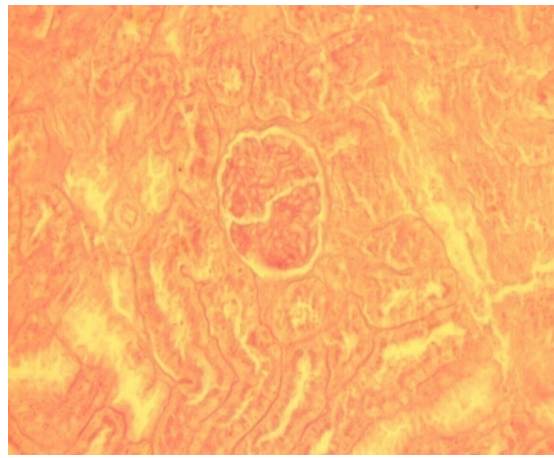

(f)

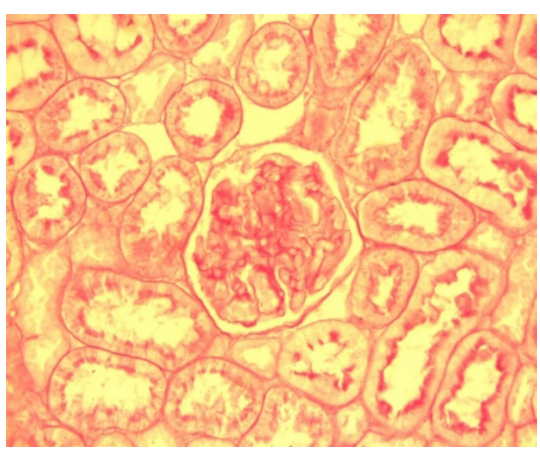

(h)

Figure 7. Histopathological examination by light microscope of diabetic rats receiving low or high dose of ramipril, or low or high dose of irbesartan in the presence or absence of insulin. Groups are shown as follows: LDR (a), HDR (b), LDRI (c), HDRI (d), LDI (e), HDI (f), LDII (g), HDII (h). 
diabetic nephropathy (i.e., MA or clinical proteinuria). Whether individuals with albumin excretion rates below the MA threshold are also at risk for CV disease or whether there is a progressive graded relationship between different degrees of albuminuria and CV events is unclear. Data also suggest that measurement of urinary albumin may help estimate the absolute risk of experiencing a CV event for individuals with or without DM (HOPE). Albuminuria is, however, linked with other risk factors that may themselves be causal or linked with causal processes. These include both diabetic and non-diabetic degrees of hyperglycemia [20], hypertension [21], renal dysfunction [22], dyslipidemia [23], hyperhomocysteinemia [24], dietary proteins [25], and smoking [26]. Albuminuria also reveals increased renal endothelial permeability [25].

Thus measurement of albuminuria as a marker of other CV factors, as well as existing renal endothelial dysfunction, is an easy tool that likely reflects underlying macro- and microvascular disease.Biochemically, our results confirmed the beneficial effect of low and high doses of both ramipril and irbesartan on urinary albumin excretion of diabetic rats as compared to non-treated diabetic rats. However, low dose irbesartan and high dose of both drugs seem to be more beneficial on urine albumin excretion. In contrast to the biochemical results, histopathological studies failed to demonstrate any beneficial effect of both drugs in diabetic rats not controlled with insulin. Experiments in rabbits have shown that atheromatous lesions were successfully prevented by a high dose of trandolapril, whereas a low dose had no effect [26], although plasma ACE activity was inhibited similarly. As for clinical investigation, the SECURE study has shown a strong dose dependency of atherosclerosis progression; a $2.5 \mathrm{mg}$ dose of ramipril did not affect it more than placebo, whereas daily ramipril of $10 \mathrm{mg}$ did [27]. Along the same lines, Parving et al. have shown a dose-response effect of the protection from ongoing kidney damage by the angiotensin receptor blocker, irbesartan, at $150 \mathrm{mg}$ and $300 \mathrm{mg}$ daily [15] [28]. The cardiovascular and renal protection by an ACE inhibitor is dose-dependent and has important implications for current clinical care and for research on prevention of cardiovascular disease by the inhibition of the renin-angiotensin system. It means that patients treated by once daily, usual doses of ACE inhibitors in hypertension trials may have experienced a lower cardiovascular benefit than could have been safely achieved if ACE inhibitors had been used at higher doses. Despite the well-known difficulties of interpretation generated by the results of "negative" randomized trials, we conclude that our results, interpreted in the context of other experimental and clinical data, show that high doses of ramipril and irbesartan are preferable to low doses in the prevention of renal events in patients at high risk of cardiovascular events [29]. However, our results showed much more beneficial effects of low and high dose irbesartan compared to ramipril especially in diabetic rats treated with insulin. The mechanism underlying the renoprotection by angiotensin II blockersmay be complex, involving lowering the intraglomerular pressure [30], the beneficial effects of diminished proteinuria [31], and decreasing collagen formation [32], that may be related to decreased stimulation of transforming growth factor $b$ by angiotensin II [33].

We cannot directly address the issue of whether the effects of ramipril and irbesartan would be equivalent in the treatment of patients with nephropathy due to T2D. It may seem reasonable to assume that agents that primarily reduce the generation or effect of angiotensin II would have similar clinical results. However, it is important to caution that ACE inhibitors and ARB are distinctly different classes of drugs and that one cannot assume equivalence between them.

The pharmacological activity of these agents is complex. The effect of ACE inhibition on renal hemodynamics could be limited by the non-ACE-dependent generation of angiotensin II that has been documented in patients in the hyperglycemic state [31].

The efficacy of ramipril in nephropathy study failed to demonstrate renoprotection in patients with nephropathy due to T2D who received ACE inhibitors [34]. Another study in patients with MA and T2D indicated that ACE inhibition slowed the progression of renal disease [35].

Our data as evidenced by histopathological results reveal that low and high doses of irbesartanin combination with insulin is more renoprotective in diabetic rats and overt nephropathy and significantly slows the progression of glomerulopathy. These benefits appear to be independent of the other parameters studied. In contrast to our study, another one has reported that there was no difference in nephropathic changes and glycemic control among patients receiving irbesartan [36]. Nevertheless, another study emphasized that improvement in glycemic control slows the increase in the level of albuminuria and postpones the occurrence of overt diabetic nephropathy in patients with T2D [37].

Our study confirms and extends the finding that antihypertensive treatment has a renoprotective effect in patients with T2D and MA. There has been conflicting evidence regarding the existence of a specific renoprotec- 
tive effect-that is, a beneficial effect on kidney function beyond the hypotensive effect—of agents, such as ACE-inhibitors, that block the RAAS system in patients with T2D and MA [38] [39]. All the other parameters of the current study showed conflicting results which are not attributed to the inhibition of the RAAS system.

\section{Conclusion}

In conclusion, low dose irbesartan and high doses of both drugs have renoprotective effect in diabetic rats treated with insulin, In the light of the conflicting information from other reports; our drawn conclusion obtained from our results should be limited to the agents and dosages that we used in this study. According to the published guidelines for the treatment of diabetic kidney disease, routine screening of urine for MA should be performed in all patients with diabetes [39] [40] just as these patients are routinely screened for diabetic retinopathy.

\section{Acknowledgements}

Special thanks to Dr. Ahmed Ismail from the department of pharmacology and toxicology in UQU for his assistance in some laboratory preparations.

\section{Declaration of Conflicting Interests}

The authors declare that there is no conflict of interest.

\section{Fund}

This project was supported by The Institute of Research and Revival of Islamic Heritage in Umm Alqura University, Kingdom of Saudi Arabia [Grant number 43209011].

\section{References}

[1] Eurich, D.T., Weir, D.L., Majumdar, S.R., Tsuyuki, R.T., Johnson, J.A., Tjosvold, L., et al. (2013) Comparative Safety and Effectiveness of Metformin in Patients with Diabetes Mellitus and Heart Failure: Systematic Review of Observational Studies Involving 34,000 Patients. Circulation Heart Failure, 6, 395-402. http://dx.doi.org/10.1161/CIRCHEARTFAILURE.112.000162

[2] Kliger, A.S., Foley, R.N., Goldfarb, D.S., Goldstein, S.L., Johansen, K., Singh, A., et al. (2013) KDOQI US Commentary on the 2012 KDIGO Clinical Practice Guideline for Anemia in CKD. American Journal of Kidney Diseases, 62, 849-859. http://dx.doi.org/10.1053/j.ajkd.2013.06.008

[3] Ravid, M., Lang, R., Rachmani, R. and Lishner, M. (1996) Long-Term Renoprotective Effect of Angiotensin-Converting Enzyme Inhibition in Non-Insulin-Dependent Diabetes Mellitus. A 7-Year Follow-Up Study. Archives of Internal Medicine, 156, 286-289. http://dx.doi.org/10.1001/archinte.1996.00440030080010

[4] UK Prospective Diabetes Study (UKPDS) Group (1998) Intensive Blood-Glucose Control with Sulphonylureas or Insulin Compared with Conventional Treatment and Risk of Complications in Patients with Type 2 Diabetes (UKPDS 33). Lancet, 352, 837-853. http://dx.doi.org/10.1016/S0140-6736(98)07019-6

[5] Ismail-Beigi, F., Craven, T., Banerji, M.A., Basile, J., Calles, J., Cohen, R.M., et al. (2010) Effect of Intensive Treatment of Hyperglycaemia on Microvascular Outcomes in Type 2 Diabetes: An Analysis of the ACCORD Randomised trial. Lancet, 376, 419-430. http://dx.doi.org/10.1016/S0140-6736(10)60576-4

[6] Lewington, S., Clarke, R., Qizilbash, N., Peto, R. and Collins, R., Prospective Studies C. (2002) Age-Specific Relevance of Usual Blood Pressure to Vascular Mortality: A Meta-Analysis of Individual Data for One Million Adults in 61 Prospective Studies. Lancet, 360, 1903-1913. http://dx.doi.org/10.1016/S0140-6736(02)11911-8

[7] The Diabetes Control and Complications (DCCT) Research Group (1995) Effect of Intensive Therapy on the Development and Progression of Diabetic Nephropathy in the Diabetes Control and Complications Trial. Kidney International, 47, 1703-1720. http://dx.doi.org/10.1038/ki.1995.236

[8] Sen, S., Kanter, M., Ustundag, S., Aktas, C., Dogutan, H. and Yalcin, O. (2008) Effect of Angiotensin-Converting enzyme Inhibition and Angiotensin II Type 1 Receptor Blockade on Streptozotocin-Induced Diabetic Nephropathy. Renal Failure, 30, 1023-1033. http://dx.doi.org/10.1080/08860220802495248

[9] Laffel, L.M., McGill, J.B. and Gans, D.J. (1995) The Beneficial Effect of Angiotensin-Converting Enzyme Inhibition with Captopril on Diabetic Nephropathy in Normotensive IDDM Patients with Microalbuminuria. North American Microalbuminuria Study Group. The American Journal of Medicine, 99, 497-504. http://dx.doi.org/10.1016/S0002-9343(99)80226-5 
[10] Remuzzi, G., Macia, M. and Ruggenenti, P. (2006) Prevention and Treatment of Diabetic Renal Disease in Type 2 Diabetes: The BENEDICT Study. Journal of the American Society of Nephrology, 17, S90-S97. http://dx.doi.org/10.1681/ASN.2005121324

[11] Psaty, B.M., Lumley, T., Furberg, C.D., Schellenbaum, G., Pahor, M., Alderman, M.H., et al. (2003) Health Outcomes Associated with Various Antihypertensive Therapies Used as First-Line Agents: A Network Meta-Analysis. JAMA, 289, 2534-2544. http://dx.doi.org/10.1001/jama.289.19.2534

[12] Haller, H., Ito, S., Izzo Jr., J.L., Januszewicz, A., Katayama, S., Menne, J., et al. (2011) Olmesartan for the Delay or Prevention of Microalbuminuria in Type 2 Diabetes. The New England Journal of Medicine, 364, 907-917. http://dx.doi.org/10.1056/NEJMoa1007994

[13] Bilous, R., Chaturvedi, N., Sjolie, A.K., Fuller, J., Klein, R., Orchard, T., et al. (2009) Effect of Candesartan on Microalbuminuria and Albumin Excretion Rate in Diabetes: Three Randomized Trials. Annals of Internal Medicine, 151, 1120.

[14] Mauer, M., Zinman, B., Gardiner, R., Suissa, S., Sinaiko, A., Strand, T., et al. (2009) Renal and Retinal Effects of Enalapril and Losartan in Type 1 Diabetes. The New England Journal of Medicine, 361, 40-51. http://dx.doi.org/10.1056/NEJMoa0808400

[15] Parving, H.H., Lehnert, H., Brochner-Mortensen, J., Gomis, R., Andersen, S., Arner, P., et al. (2001) The Effect of Irbesartan on the Development of Diabetic Nephropathy in Patients with Type 2 Diabetes. The New England Journal of Medicine, 345, 870-878. http://dx.doi.org/10.1056/NEJMoa011489

[16] Schjoedt, K.J., Jacobsen, P., Rossing, K., Boomsma, F. and Parving, H.H. (2005) Dual Blockade of the Renin-AngiotensinAldosterone System in Diabetic Nephropathy: The Role of Aldosterone. Hormone and Metabolic Research, 37, 4-8.

[17] Schjoedt, K.J., Rossing, K., Juhl, T.R., Boomsma, F., Rossing, P., Tarnow, L., et al. (2005) Beneficial Impact of Spironolactone in Diabetic Nephropathy. Kidney International, 68, 2829-2836. http://dx.doi.org/10.1111/j.1523-1755.2005.00756.x

[18] Masiello, P., Broca, C., Gross, R., Roye, M., Manteghetti, M., Hillaire-Buys, D., et al. (1998) Experimental NIDDM: Development of a New Model in Adult Rats Administered Streptozotocin and Nicotinamide. Diabetes, 47, $224-229$. http://dx.doi.org/10.2337/diab.47.2.224

[19] Matsumoto, H., Uchino, M. and Kato, M. (2013) Evaluation of Haemoglobin A1c Measurement by an Enzymatic Method Using an Automated Analyser That Has an On-Board Haemolysis System. Annals of Clinical Biochemistry, 50, 443-449. http://dx.doi.org/10.1177/0004563213476859

[20] Niskanen, L., Turpeinen, A., Penttila, I. and Uusitupa, M.I. (1998) Hyperglycemia and Compositional Lipoprotein Abnormalities as Predictors of Cardiovascular Mortality in Type 2 Diabetes: A 15-Year Follow-Up from the Time of Diagnosis. Diabetes Care, 21, 1861-1869. http://dx.doi.org/10.2337/diacare.21.11.1861

[21] Agrawal, B., Berger, A., Wolf, K. and Luft, F.C. (1996) Microalbuminuria Screening by Reagent Strip Predicts Cardiovascular Risk in Hypertension. Journal of Hypertension, 14, 223-228. http://dx.doi.org/10.1097/00004872-199602000-00011

[22] Shulman, N.B., Ford, C.E., Hall, W.D., Blaufox, M.D., Simon, D., Langford, H.G., et al. (1989) Prognostic Value of Serum Creatinine and Effect of Treatment of Hypertension on Renal Function. Results from the Hypertension Detection and Follow-Up Program. The Hypertension Detection and Follow-Up Program Cooperative Group. Hypertension, 13, I80-I93. http://dx.doi.org/10.1161/01.HYP.13.5 Suppl.I80

[23] Hoogeveen, E.K., Kostense, P.J., Jager, A., Heine, R.J., Jakobs, C., Bouter, L.M., et al. (1998) Serum Homocysteine Level and Protein Intake Are Related to Risk of Microalbuminuria: The Hoorn Study. Kidney International, 54, 203209. http://dx.doi.org/10.1038/sj.ki.4495353

[24] Forsblom, C.M., Groop, P.H., Ekstrand, A., Totterman, K.J., Sane, T., Saloranta, C., et al. (1998) Predictors of Progression from Normoalbuminuria to Microalbuminuria in NIDDM. Diabetes Care, 21, 1932-1938. http://dx.doi.org/10.2337/diacare.21.11.1932

[25] Stehouwer, C.D., Nauta, J.J., Zeldenrust, G.C., Hackeng, W.H., Donker, A.J. and den Ottolander, G.J. (1992) Urinary Albumin Excretion, Cardiovascular Disease, and Endothelial Dysfunction in Non-Insulin-Dependent Diabetes Mellitus. The Lancet, 340, 319-323. http://dx.doi.org/10.1016/0140-6736(92)91401-S

[26] Chobanian, A.V., Hope, S. and Brecher, P. (1995) Dissociation between the Antiatherosclerotic Effect of Trandolapril and Suppression of Serum and Aortic Angiotensin-Converting Enzyme Activity in the Watanabe Heritable Hyperlipidemic Rabbit. Hypertension, 25, 1306-1310. http://dx.doi.org/10.1161/01.HYP.25.6.1306

[27] Lonn, E., Yusuf, S., Dzavik, V., Doris, C., Yi, Q., Smith, S., et al. (2001) Effects of Ramipril and Vitamin E on Atherosclerosis: The Study to Evaluate Carotid Ultrasound Changes in Patients Treated with Ramipril and Vitamin E (SECURE). Circulation, 103, 919-925. http://dx.doi.org/10.1161/01.CIR.103.7.919

[28] Rabbat, C.G. (2002) Irbesartan Was Renoprotective in Patients with Type 2 Diabetes, Hypertension, and Microalbu- 
minuria. ACP Journal Club, 136, 82-84.

[29] Maillard, M.P., Wurzner, G., Nussberger, J., Centeno, C., Burnier, M. and Brunner, H.R. (2002) Comparative Angiotensin II Receptor Blockade in Healthy Volunteers: The Importance of Dosing. Clinical Pharmacology and Therapeutics, 71, 68-76. http://dx.doi.org/10.1067/mcp.2002.121425

[30] Kagami, S., Border, W.A., Miller, D.E. and Noble, N.A. (1994) Angiotensin II Stimulates Extracellular Matrix Protein Synthesis through Induction of Transforming Growth Factor-Beta Expression in Rat Glomerular Mesangial Cells. The Journal of Clinical Investigation, 93, 2431-2437. http://dx.doi.org/10.1067/mcp.2002.121425

[31] Osei, S.Y., Price, D.A., Laffel, L.M., Lansang, M.C. and Hollenberg, N.K. (2000) Effect of Angiotensin II Antagonist Eprosartan on Hyperglycemia-Induced Activation of Intrarenal Renin-Angiotensin System in Healthy Humans. Hypertension, 36, 122-126. http://dx.doi.org/10.1161/01.HYP.36.1.122

[32] Zatz, R., Dunn, B.R., Meyer, T.W., Anderson, S., Rennke, H.G. and Brenner, B.M. (1986) Prevention of Diabetic Glomerulopathy by Pharmacological Amelioration of Glomerular Capillary Hypertension. The Journal of Clinical Investigation, 77, 1925-1930. http://dx.doi.org/10.1172/JCI112521

[33] Abbate, M., Zoja, C., Corna, D., Capitanio, M., Bertani, T. and Remuzzi, G. (1998) In Progressive Nephropathies, Overload of Tubular Cells with Filtered Proteins Translates Glomerular Permeability Dysfunction into Cellular Signals of Interstitial Inflammation. Journal of the American Society of Nephrology: JASN, 9, 1213-1224.

[34] Wolf, G., Haberstroh, U. and Neilson, E.G. (1992) Angiotensin II Stimulates the Proliferation and Biosynthesis of Type I Collagen in Cultured Murine Mesangial Cells. The American Journal of Pathology, 140, 95-107.

[35] Ruggenenti, P., Perna, A., Gherardi, G., Benini, R. and Remuzzi, G. (2000) Chronic Proteinuric Nephropathies: Outcomes and Response to Treatment in a Prospective Cohort of 352 Patients with Different Patterns of Renal Injury. American Journal of Kidney Diseases: The Official Journal of the National Kidney Foundation, 35, 1155-1165. http://dx.doi.org/10.1016/S0272-6386(00)70054-0

[36] Ravid, M., Savin, H., Jutrin, I., Bental, T., Katz, B. and Lishner, M. (1993) Long-Term Stabilizing Effect of Angiotensin-Converting Enzyme Inhibition on Plasma Creatinine and on Proteinuria in Normotensive Type II Diabetic Patients. Annals of Internal Medicine, 118, 577-581. http://dx.doi.org/10.7326/0003-4819-118-8-199304150-00001

[37] Lewis, E.J., Hunsicker, L.G., Clarke, W.R., Berl, T., Pohl, M.A., Lewis, J.B., et al. (2001) Renoprotective Effect of the Angiotensin-Receptor Antagonist Irbesartan in Patients with Nephropathy Due to Type 2 Diabetes. The New England Journal of Medicine, 345, 851-860. http://dx.doi.org/10.1056/NEJMoa011303

[38] Heart Outcomes Prevention Evaluation (HOPE) Study Investigators (2000) Effects of Ramipril on Cardiovascular and Microvascular Outcomes in People with Diabetes Mellitus: Results of the HOPE Study and MICRO-HOPE Substudy. The Lancet, 355, 253-259. http://dx.doi.org/10.1016/S0140-6736(99)12323-7

[39] Mogensen, C.E., Keane, W.F., Bennett, P.H., Jerums, G., Parving, H.H., Passa, P., et al. (1995) Prevention of Diabetic Renal Disease with Special Reference to Microalbuminuria. The Lancet, 346, 1080-1084. http://dx.doi.org/10.1016/S0140-6736(95)91747-0

[40] American Diabetes Association (2014) Standards of Medical Care in Diabetes—2014. Diabetes Care, 37, S14-S80. http://dx.doi.org/10.2337/dc14-S014 


\section{Abbreviations and Symbols}

NC (Normal Control);

DR (Diabetic Rats);

DRI (Diabetic Rats Treated with insulin);

LDR (Low Dose Ramipril);

HDR (High Dose Ramipril);

LDI (Low Dose Irbesartan);

HDI (High Dose Irbesartan);

LDRI (Low Dose Ramipril Treated with insulin);

HDRI (High Dose Ramipril Treated with insulin);

LDII (Low Dose Irbesartan Treated with insulin);

HDII (High Dose Irbesartan Treated with insulin);

FBS (Fasting blood sugar);

HbA1c (glycosylated hemoglobin);

TG (triglycerides);

TC (total cholesterol);

LDL-C (low density lipoprotein cholesterol);

HDL-C (high density lipoprotein cholesterol);

Statistically significant $(P<0.05)$ as compared to control rats $(*)$ and statistically significant $(P<0.05)$ as compared to diabetic rats $(\bullet)$. 